\title{
STRATEGIC MANAGEMENT PROCESS AND FIRM'S PRODUCTIVITY OF PLASTIC MANUFACTURING COMPANIES IN SOUTH-SOUTH, NIGERIA
}

\author{
${ }^{1}$ Bayo, P.L. (PhD) and ${ }^{2}$ Ebikebena E. Red-well \\ Department of Management, Faculty of Management Sciences, \\ Rivers State University, Port Harcourt, Nigeria \\ bayo.princewill@ust.edu.ng, redwellemotongha@yahoo.com
}

\begin{abstract}
The study examines how strategic management process affects firm productivity with specific reference to plastic manufacturing companies listed in the manufacturer association of Nigeria that has operational based in the South-South, Nigeria. The study employed crosssectional survey design which is exploratory in nature because the data were collected at a particular point in time to examine how strategic management process affect productivity in the context of Nigeria plastic manufacturing sector.The population for the study was all the 34 plastic manufacturing companies listed in the 2018 edition of the directory of Nigerian manufacturer Association based in South-South Nigeria. The cluster sampling technique was adopted in this study. This was complemented with the simple random sampling technique. The analytical techniques employed were Correlation and Multiple Regression Statistics to determine the strength and direction of the relationship and test the hypotheses with the help of IBM data editor of Statistical Package for the Social Sciences. The findings of the study revealed thatthere is a significant relationship between strategy formulation, strategy implementation and productivity in the context of Nigeria plastic manufacturing sector. Furthermore, the findings showed that there is no significant relationship between strategy evaluation and productivity in the context of Nigeria plastic manufacturing sector. The study concludes that strategy formulation, strategy implementation, strategy evaluation makes a unique contribution to the variation of plastic manufacturing firms' level of productivity to gain edge over rivals in the industry. Therefore, the study recommends that plastic manufacturing firms should implement formulated policies and strategies to match with the structure of the organization, increase value relevance and earnings quality for productivity.
\end{abstract}

Key Words: Strategic Management Process, Strategy Formulation, Strategy Implementation, Strategy Evaluation, Productivity. 


\section{Introduction}

Nigeria is the largest black nation with a population of over 200 million people and has a vast sectoral economy (National Bureau of Statistics, 2019). This statistic depicts the production volume of plastic in Nigeria from 2007 to 2015, and estimated figures from 2016 to 2020. In 2015 , the production volume of plastic in Nigeria reached around 411,000 tons. This figure is expected to increase to some 513,000 tons of plastic by 2021. In Nigeria, the industry occupies an important position in the economy and has great potentials of becoming one of the biggest markets in the world, yet it level of productivity to meet the projected estimates makes no differences to the growth of the economy (Aibinu and Jagboro, 2002). Thus; productivity is an overall measure of the ability to produce a good or service. More specifically, productivity is the measure of how specified resources are managed to accomplish timely objectives as stated in terms of quantity and quality. Furthermore, productivity is useful as a relative measure of actual output of production compared to the actual input of resources, measured across time or against common entities. As output increases for a level of input, or as the amount of input decreases for a constant level of output, an increase in productivity occurs. Similarly, the productivity definition of Bernolak conforms to the generic interpretation of service by Vargo and Lusch (2004) and Penrose (1959). They posits that if the resources are understood as consisting of all human and physical assets, productivity results from the overall delivery of services by the resources, which are used in the productive activities of the firm.

However, the linkage between strategic management process and firm productivity needs analysis to get a superior understanding on how strategic management process is applied in practice and to improve resources needed to attain goal in the manufacturing firms. According to Bianca (2017) for strategic management to be effective and useful, there must be commitment and involvement across all levels of the organization, overcome inherent problems such as; rival among departments, projects, resistance to change, resource requirement, resources allocation and so on. Strategic management is the process of making decision, planning, coordinating and taking some actions by the top managers of a company in order to achieve set goals and objectives. Decisions are of little use unless they are acted upon. Firms must take the necessary actions to implement their strategies and it requires top managers to allocate the necessary resources and to design the organization to bring the intended strategies to improve output quality (Dess, 2005). According to Wagner (2006) the importance of strategic management process can be explained from four points of view including environmental scanning, strategy formulation, and linking goals to budgets and implementation process.

Steiner, (2009) further argues that strategic management system provides the framework for formulating and implementing strategies. However, it is argued that for strategic management to translate into results, a facilitative internal environment and culture must be present. Though numerous studies have been done regarding strategic management in the context of Nigeria and western countries, Strickland and Gamble (2007) study strategic management and organizational performance in Banking Sector in Lagos, also Wagner, (2006) study strategy management and organizational growth in entertainment industry in Lagos. Men and Wang (2008) investigated the quality of strategy management information which is contained in the annual reports of steel sector listed corporations in the previous two years. In Africa, strategic management has been found to be having a positive impact on firms' profitability in the insurance industry. There is also a high and positive correlation between strategic management and service delivery in the Nigerian insurance industry (Alaka, Tijani \& Abass, 
2011). The corporate performance of Five Nigerian brewing companies that carry out strategic management namely Nigerian Breweries Plc, Guinness Nigerian Plc, Consolidated Breweries Plc, International Breweries Plc, Champion Breweries Plc and was suggested to be pivotal to the performance of brewing companies (Emeka, 2015). Though existing literature found that strategic management has a positive effect on firm performance, empirical substantiation which supports this proposition is mainly circumstantial or narrowed down to a small number of qualitative case studies, and mixed methods both Nigeria context and western industries. Elwak, 2013) found that strategic management process is an importance determinant of organizational productivity, although it has been ignored in the plastic industry in Nigeria. Aldehayyat and Twaissi (2011), opines that there is a strong positive relationship between strategic management and organizational performance although the extent to which strategic management contributes to improvement of productivity is still a matter of argument because of the varied results which are found in empirical research (Arasa $\&$ K'Obonyo, 2012). Hence, the purpose of this paper was sought to establish how strategic management process affects firm productivity with specific reference to plastic manufacturing companies listed in the manufacturer association of Nigeria. The questions are in line with the purpose of the paper: how does strategy formulation affect productivity. To what extent does strategy implementation affect productivity. How does strategy evaluation affect productivity.

\section{LITERATURE REVIEW}

\section{Theoretical Review}

The study of strategic management process and firm productivity was domiciled on Penrose's (1959) Resource Based theory. The resource based theory of the firm (RBT) draws focus to firms' internal environment as an enabler for competitive moves and accentuates the resources that organizations have established to compete in the business environment. The origins of the RBV was trace back to the work of Penrose (1959), who suggested that the resources possessed, deployed and used by the organization are really more important than industry structure. Since then researchers, such as Ansoff (1965) and Chandler (1962) have also made significant contributions towards the emergent and development of the resource based view of strategy (Hoskisson, Hitt, Wan \& Yiu, 1999). Organizations that effectively leverage on strategically important resources and competencies will provide a firm with a potential competitive edge to outperform competitors and increase level productivity in any industry.

\section{CONCEPTUAL REVIEW}

\section{Strategic Management Process}

Strategy is defined as the determination of the basic long-term goals of an enterprise, and the adoption of courses of action and the allocation of resources necessary for carrying out these goals. Strategic management is the process and approach of specifying an organization's objectives, developing policies and plans to achieve and attain these objectives, and allocating resources so as to implement the policies and plans (David, 2005). Thompson and Strickland (2003 cited by Fubara \& Hamilton, 2014) defined strategic management as the process whereby managers establish an organization's long-term direction, set specific performance objectives, develop strategies to achieve these objectives in the light of all the relevant internal and external circumstances, and undertake to execute the chosen action plans. 
Furthermore, studies on strategic management literature has shown that strategic management process is concerned with deciding on strategy and planning how that strategy is to be put in to effect (Aluko, 2004). It can be thought of as having three elements within it: there is strategic choice stage which is to' do with formulation of possible courses of action, their evaluation and the choice between them (Oyedijo \& Akinlabi, 2008). Finally, there is a strategic implementation stage which is to do with planning how the choice of strategy can be put into effect (Johnson \& Scholes, 2002). However, strategic management is an on-going process that evaluates and controls the business and the industries in which the firm is involved, assesses its competitors, set goal and strategies to meet all existing and potential competitors and then reassesses each strategy to meet charged circumstances, new technology, new competitors, a new economic environment or a new social financial or political environment (Muogbo, 2013).

\section{Strategy Formulation}

Strategy formulation refers to the process through which a firm defines its overall long-term direction and scope. It involves establishing the way a company creates value through the configuration of its activities and resources in the markets in which it operates. Strategy formulation is a purposeful, deliberate exercise to develop a company's competitive advantage and thus enhance its performance (Gimbert, Bisbe, \& Mendoza, 2010). The strategy formulation phase is a strategy that aims at ensuring that organizations achieve their objectives. David (2005) stated that strategy formulation include deciding which business to pursue, how to allocate resources without aggressive takeovers and whether to enter international markets. He also added that strategy formulation phase comprises development of a mission statement, identification of external opportunities and threats, determination of internal strengths and weaknesses, establishing long-term objectives, generating alternative strategies, and choosing the best strategy to be implemented (Onwuchekwa, 2012). In order to accomplish the objectives which they have set, organizations formulate appropriate strategies which give rise to development of organization structure through which the set objectives will be achieved, hence in strategic management process; organizations choose appropriate organizational structure that matches the environment in which the organization operates as well as the productive activities of the organization and this is done by the strategist such that the organization is not taken by surprise, which could lead to some losses in investment caused by the new changes (Rose \& Cray, 2010).

\section{Strategy Implementation}

The second phase of the process is strategy implementation which initiates activities in accordance to strategic plans (Sharplin, 1985). This requires firms to establish objectives, devise policies, motivate employees, and allocate resources to execute formulated strategies. Certo and Peter (1991) stated that without the effective strategy implementation, organizations are unable to reap the benefits of performing an organizational analysis, establishing organizational direction, and formulating organizational strategy. Strategic implementation, concerns with the day-to-day activities of managing the strategy to achieve strategic goals of the organization. Thus, once plans are developed, they must be actively managed and implemented to maintain the momentum of the strategy. Strategic thinking and periodic planning should never stop; they become ingrained in the culture and philosophy of a strategically managed organization. As part of managing the strategy, strategic momentum: is the actual work to accomplish specific objectives, concerns decision-making processes and their consequences, provides the style and culture, fosters anticipation, innovation, and 
excellence, evaluates strategy performance through control, is a learning process, and relies on and reinforces strategic thinking and periodic strategic planning (Swayne, Duncan, \& Ginter, 2006).

Strategic implementation ensures an ongoing philosophy for developing and managing the plans, actions, and control of the organization. It attempts to continually orchestrate a fit between the organization's external environment (political, regulatory, economic, technological, social, and competitive forces) and its internal situation (culture, organization structure, resources, products and services, and so on. In some cases, orchestrating the fit may mean responding to external forces; in other cases, the organization may attempt to actually shape its environment (change the rules for success). However, when such dramatic changes occur, new opportunities emerge and new competencies are born, while others die or are rendered inconsequential (Mische, 2001).

\section{Strategy Evaluation}

According to Strydom (2011), strategy evaluation and control inform the managers about the reasons leading to the failure to meet a certain objective, performance standard and/or any other performance indicator. Strategy evaluation and control requires information to be obtained on strategic performance and comparing it with existing standards (Certo and Peter, 1991). Evaluation is also done by reviewing current strategies, measuring performance and taking corrective actions. Strategy evaluation is needed because success today is no guarantee of success tomorrow. Success always creates new and different problems; complacent organizations experience demise (David, 2005). Strategy evaluation is a critical tool for managers to understand reasons behind failures and success of certain objectives, performance standard and/or any other performance indicator (Strydom, 2011).

More so, strategy evaluation process identifies the level of strategy implementation (Elshamly, 2013), it gives early signals about factors that might hinder the success of the strategy by prompting management to ask questions on the execution process or the leaders' reliability and competency (Carpenter \& Sanders, 2009). Strategy evaluation process highlights firms' effectiveness in reacting to new challenges (Johnson \& Scholes, 2002) that make them achieve their strategic aims. Strategy evaluation process ensures that firms adapt their strategy to any risk of changes in the environment. Arguably, a robust strategy evaluation process provides information to the management on the cause of failure in achieving the firm's strategic objective. Indeed, strategy evaluation protects the business from collapse (Dubihlela \& Sandada, 2014), prevents firms from taking wrong decisions and helps them to anticipate problems if there is change in the internal and external environment (Elshamly, 2013). Therefore, firms need to evaluate their strategies on a continuous basis (King'ola, 2001; Tunji, 2013) so that corrective action could be taken to eliminate the problems that hinder the achievement of firm objectives (David, 2011).

\section{Firm Productivity}

Productivity is the extent to which an organization's resources are brought together and effectively utilized for attainment of set goal (Bayo \& Redwell, 2020). A seminal work by Ansoff (1965) posits that productivity is usually analyzed based on two dimensions, timeliness and delivery while the former represents the ability of a service organization to fulfill its customers demands, doing the right things, the latter one represents an organization's ability to produce a specified output using as few input resources as possible, doing things right. Furthermore, productivity sees as an index that measures output (goods 
and services) relative to the input (labor, materials, energy, etc., used to produce the output). As quality assessment requires a benchmark, it is implicitly assumed that the relevant characteristics of the output can be prescribed objectively prior to the production or the relevant characteristics of the output is learnt and evaluated subjectively in the market.

However, with regard to the quality of the resources and the output the general implication of productivity is symmetric. A higher productivity of activities is attainable through a decrease of wasted and idle resources or through a higher volume and the quality of the output. However, firm productivity is vital for the success of every organization and profitability in this dynamic environment (Chien, 2004); it is conceptualized as the individual's investment of his complete self into a role. Productivity and output are two indispensadable elements of an organizational life, because without increased and sustained output on the part of the employees, the organization risk poor performance outcome in general and if not controlled or corrected will lead to extinction of that organization. 


\section{Operational Model of Strategic Management Process and Firm Productivity}

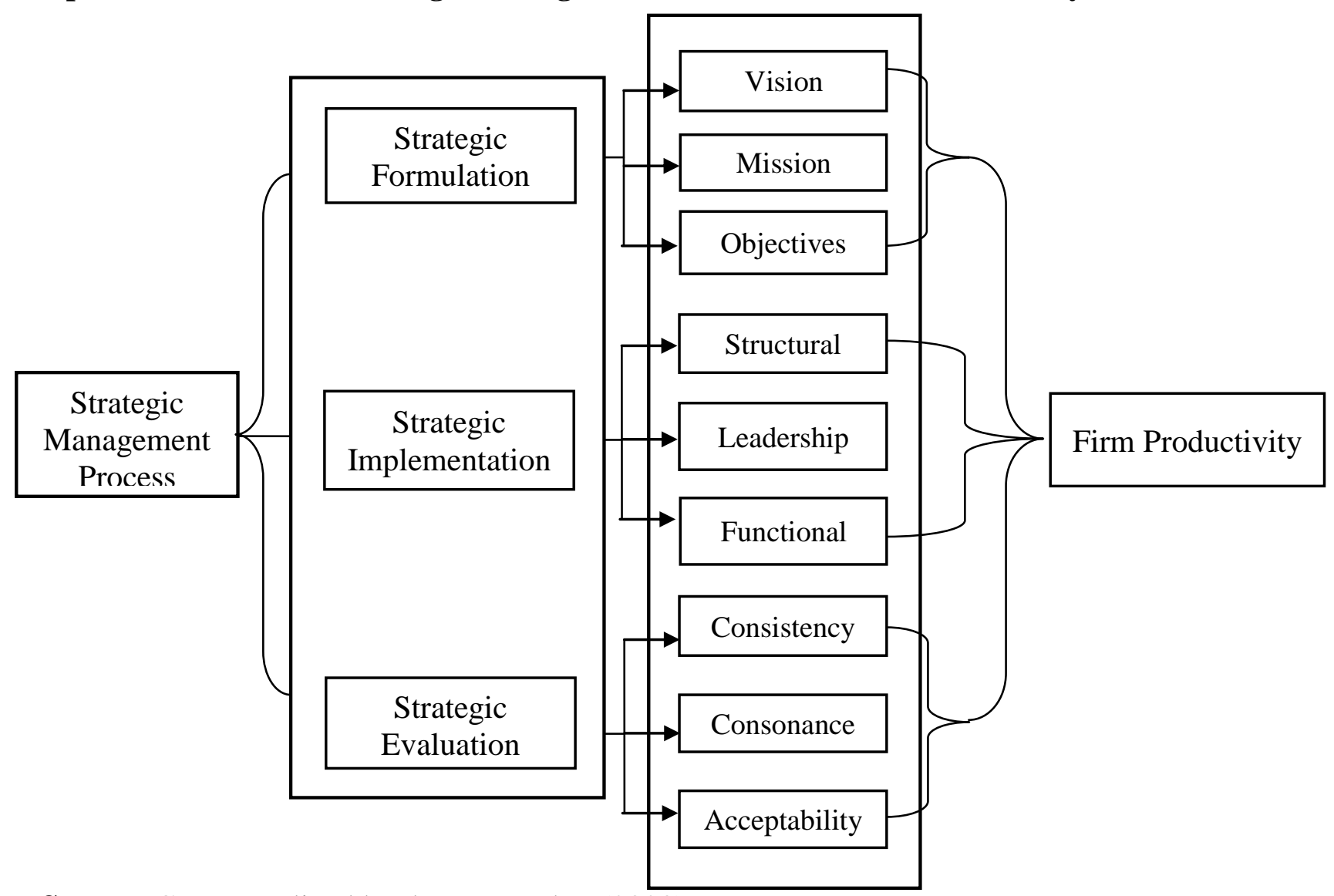

Source: Conceptualized by the Researcher (2020)

\section{Empirical Review}

Prior studies on the interrelationship between strategy process (formulation) and product innovation performance show a significant positive correlation between the two variables (Acar \& Acar, 2012). In the same direction, Zhang (2009) found that both the formulation and implementation processes through their influence on type of information needed, the source of information and the interplay among difference pieces of information are positively correlated to innovation performance of organizations. Ogunmokun (2005) study strategy implementation and organizational performance using private hospitals as its case study; the study found that the extent to which these private hospitals carry out their strategic implementation activities are related to the level of their organizational productivity.

Ibrahim \& Mohamed (2012) study the relationship between strategy implementation and performance of manufacturing firms in Indonesia using formality structure as a Moderator. The study was carried out to examine the connection amid strategy implementation and firm performance. It also examined the moderating role of formalization on the connection amid strategy implementation and performance of manufacturing firms in Indonesia. The population of the study was the manufacturing companies listed in the Jakarta Stock Exchange (JSE). The results of the research work show that there was a significant relationship between strategy implementation and performance of the manufacturing firms. The results also showthat there was a moderating upshot of formalization on the relationship 
between strategy implementation (program of budget and control of resources) and performance of the manufacturing firms measured by Return on Equity (ROE).

Wanjiru (2016) examined the influence of strategic evaluation practices on corporate performance. The results showed that strategy evaluation has a significant influence on the performance of Sarova town hotels. Similarly, Maroa and Muturi (2015) investigated the relationship between strategic evaluation practices and performance of flower firms in Kenya. It was observed that most floricultural firms evaluated their strategy and strategy evaluation had a significant influence on the performance of flower firms. Kumar (2015) using correlation analysis found that the strategy evaluation dimension of strategic planning steps have a significant and positive association with firm performance. Authors argue that strategy evaluation is a systematic and rational process that influences the performances of mobile telecommunication firms in Nigeria. The above empirical review gives birth to the following hypotheses.

Ho$_{1}$ : There is no significant relationship between strategy formulation and productivity in the plastic manufacturing companies in South-South, Nigeria

Ho2: There is no significant relationship between strategy implementation and productivity in the plastic manufacturing companies in South-South, Nigeria

Ho3: There is no significant relationship between strategy evaluation and productivity in the plastic manufacturing companies in South-South, Nigeria

\section{Methodology}

The study employed cross-sectional survey design which is exploratory in nature because the data were collected at a particular point in time to examine how strategic management process affect productivity in the context of Nigeria plastic manufacturing sector. The population for the study was all the 34 plastic manufacturing companies listed in the 2018 edition of the directory of Nigerian manufacturer Association based in South-South Nigeria. The cluster sampling technique was adopted in this study. This was complemented with the simple random sampling technique. The reason for the choice is that the population of study: (34 plastic firms listed on the Manufacturer Association of Nigeria) South-South is distributed into five cluster/ category.

Cluster sampling technique was used in the sample selection, such that the number of respondents selected from each state will represent its share of the entire population. For each company in a give cluster/ state to have equal chance of being selected, the simple random sampling technique was then introduced to arrive at a sample of 27 companies to be study. This is because in this sampling method, each member of the population has a known and equal probability of being chosen. It is a probabilistic sampling procedure. Primary data was collected through designed questionnaire to be distributed to the firms listed in the 2018 edition of the directory of Nigerian manufacturer Association based in South-South Nigeria. The research instrument was subject to content and face validity. However, Cronbach Alpha index was used for estimating the reliability of the questionnaire. Favorable reliable scores were obtained from all the items since all the values were above the 0.7 exceeding the threshold of Cronbach Alpha value recommended by (Nunnaly, 1970) as showed in the table below: 
Table 1 Reliability Results

\begin{tabular}{lll}
\hline & Measures & Alpha Coefficients. \\
\hline \multirow{3}{*}{ Variables } & Strategy Formulation & 0.970 \\
& Strategy Implementation & 0.960 \\
& Strategy Evaluation & 0.971 \\
& Productivity & 0.956 \\
\hline
\end{tabular}

Source: Research survey, 2020

The analytical techniques employed were correlation and Multiple Regression Statistics to determine the strength and direction of the relationship and test the hypotheses with the help of IBM data editor of Statistical Package for the Social Sciences (SPSS 23.0).

\section{Data Analysis and Results}

Analysis of Research Questions: the analysis was carried out using Spearman's rank order correlation coefficients statistical techniques with the help of statistical package for social science (SPSS version, 23) at a 95\% confidence interval to analyze the research questions in the study.

\section{Table 2: Correlation Matrix Analysis for Strategy Formulation, Strategy Implementation, Strategy Evaluation and Productivity \\ Correlations}

\begin{tabular}{|c|c|c|c|c|c|c|}
\hline & & & $\begin{array}{c}\text { Strategy } \\
\text { Formulation }\end{array}$ & $\begin{array}{c}\text { Strategy } \\
\text { Implementation }\end{array}$ & $\begin{array}{c}\text { Strategy } \\
\text { Evaluation }\end{array}$ & $\begin{array}{c}\text { Firm } \\
\text { Productivity }\end{array}$ \\
\hline \multirow{12}{*}{$\begin{array}{l}\text { Spearman's } \\
\text { rho }\end{array}$} & \multirow{3}{*}{$\begin{array}{l}\text { Strategy } \\
\text { Formulation }\end{array}$} & Correlation Coefficient & 1.000 & & & \\
\hline & & Sig. (2-tailed) & & & & \\
\hline & & $\mathrm{N}$ & 27 & & & \\
\hline & \multirow{3}{*}{$\begin{array}{l}\text { Strategy } \\
\text { Implementation }\end{array}$} & Correlation Coefficient & $.982^{\prime \prime}$ & 1.000 & & \\
\hline & & Sig. (2-tailed) & .000 & . & & \\
\hline & & $\mathrm{N}$ & 27 & 27 & & \\
\hline & \multirow{3}{*}{$\begin{array}{l}\text { Strategy } \\
\text { Evaluation }\end{array}$} & Correlation Coefficient & $.977^{\pi \times}$ & $.974^{\pi \pi}$ & 1.000 & \\
\hline & & Sig. (2-tailed) & .000 & .000 & . & \\
\hline & & $\mathrm{N}$ & 27 & 27 & 27 & \\
\hline & \multirow{3}{*}{$\begin{array}{l}\text { Firm } \\
\text { Productivity }\end{array}$} & Correlation Coefficient & $.958^{\star x}$ & $.952^{x \times}$ & $.964^{\pi x}$ & 1.000 \\
\hline & & Sig. (2-tailed) & .000 & .000 & .000 & $\cdot$ \\
\hline & & $\mathrm{N}$ & 27 & 27 & 27 & 27 \\
\hline
\end{tabular}

${ }^{\star \star}$. Correlation is significant at the 0.01 level (2-tailed).

Table 2 showed the relationship between strategy formulation, strategy implementation, strategy evaluation and productivity. The result showed that strategy formulation, strategy implementation, strategy evaluation has a very strong positive relationship with productivity ( $r h o=0.958$; rho $=0.952$; rho $=0.964$ ). This finding provides a solution to research question $1,2,3$ and represents high correlation indicating dependable relationship between the both variables of the study. 
Journal DOI: $w$ ww.doi.org/10.46654/RJMP

Article DOI: www.doi.org/10.46654/RJMP.117113

Table 3 Model 1: Showed the Effect of Strategic Management Process (Strategy Formulation, Strategy Implementation, Strategy Evaluation) on Productivity

Model Summary

\begin{tabular}{|c|c|c|c|c|}
\hline Model & $\mathrm{R}$ & R Square & Adjusted R Square & Std. Error of the Estimate \\
\hline$\overline{1}$ & $.980^{\mathrm{a}}$ & .960 & .959 & .62126 \\
\hline
\end{tabular}

a. Predictors: (Constant), strategy evaluation , strategy implementation, strategy formulation

Model 1, above showed the result of regression analysis (R-value 0.980) between the criterion variable (productivity) and the predictor variable strategic management process (strategy formulation, strategy implementation, strategy evaluation) that taken together. The (R-value $=0.980$ ) indicates that the strategic management process has a strong influence on productivity. The coefficient of determination $\left(\mathrm{R}^{2}\right.$-value .960$)$ implies that both predictor variables explain $96 \%$ variance on productivity.

Table 4: Multiple Regression Analysis Showing Strategic Management Process (Strategy Formulation, Strategy Implementation, Strategy Evaluation) and Productivity

Coefficients $^{\mathrm{a}}$

\begin{tabular}{llrrrrrr}
\hline & & \multicolumn{2}{c}{ Unstandardized Coefficients } & Standardized Coefficients & & \\
\cline { 3 - 7 } Model & B & \multicolumn{3}{c}{ Std. Error } & Beta & \multicolumn{1}{c}{ Sig. } \\
\hline 1 & (Constant) & .587 & .304 & & 1.928 & .055 \\
& strategy formulation & .459 & .075 & .507 & 6.078 & .000 \\
& strategy implementation & .481 & .078 & .468 & 6.156 & .000 \\
strategy evaluation & .008 & .054 & .010 & .147 & .883 \\
\hline
\end{tabular}

a. Dependent Variable: Firm productivity

\section{Test of Hypotheses}

Decision Rule: if the P-value calculated is less than the critical level of significance, the study reject the null hypothesis and accept the alternate. Otherwise the study rejects the alternate hypothesis and accepts the null of no significant relationship in the study.

Ho $_{1}$ : There is no significant relationship between strategy formulation and productivity in the plastic manufacturing companies in South-South, Nigeria

Table 4 above indicates the result of regression coefficient for strategy formulation and productivity with a $\left(\mathrm{t}-\mathrm{cal}_{\mathrm{c}}=6.078\right)$ and significant level of $(\mathrm{P}=0.000<0.05 \%)$. The $(\mathrm{P}=000<0.05 \%)$ showed that there is a significant relationship between strategy formulation and productivity. Thus, the alternate hypothesis is hereby accepted. Similarly strategy formulation as a predictor variable makes $(\beta=0.459)$ contributes to the variation of the criterion variable (productivity) in the plastic manufacturing companies in South-South, Nigeria.

$\mathrm{Ho}_{2}:$ There is no significant relationship between strategy implementation and productivity in the plastic manufacturing companies in South-South, Nigeria.

Table 4 above indicates the result of regression coefficient for strategy implementation and productivity with a $\left(\mathrm{t}_{-\mathrm{cal}}=6.156\right)$ and significant level of $(\mathrm{P}=0.000<0.05 \%)$. The $(\mathrm{P}=000<0.05 \%)$ 
Journal DOI: www.doi.org/10.46654/RJMP

Article DOI: www.doi.org/10.46654/RJMP.117113

showed that there is a significant relationship between strategy implementation and productivity. Thus, the alternate hypothesis is hereby accepted. Similarly strategy implementation as a predictor variable makes $(\beta=0.481)$ contributes to the variation of the criterion variable (productivity) in the plastic manufacturing companies in South-South, Nigeria.

\section{Ho.: There is no significant relationship between strategy evaluation and} productivity in the plastic manufacturing companies in South-South, Nigeria.

Table 4 above indicates the result of regression coefficient for strategy formulation and productivity with a $\left(\mathrm{t}_{-\mathrm{cal}}\right.$. $\left.=0.147\right)$ and significant level of $(\mathrm{P}=0.883>0.05 \%)$. The $(P=0.883>0.05 \%)$ showed that there is no significant relationship between strategy evaluation and productivity. Thus, the alternate hypothesis is hereby rejected. Similarly strategy evaluation as a predictor variable makes $(\beta=0.008)$ little contributes to the variation of the criterion variable (productivity) in the plastic manufacturing companies in South-South, Nigeria.

\section{Discussion of Findings}

The findings of the study showed that strategy formulation, strategy implementation has a significant relationship with productivity in the plastic manufacturing firms in the south-south Nigeria. The findings in line with the conclusions of Askarany and Yazdifar (2012) findings suggest a significant association between the diffusion of these relatively new strategic management tools and organizational performance. In the same direction, Zhang (2009) found that both the formulation and implementation processes through their influence on type of information needed, the source of information and the interplay among difference pieces of information are positively correlated to innovation performance of organizations. The findings reinforce previous studies like Ogunmokun (2005) who found that the extent to which these private hospitals carry out their strategic implementation activities are related to the level of their organizational productivity.

Also Ibrahim \& Mohamed (2012) results of the research work shows that there was a significant relationship between strategy implementation and performance of the manufacturing firms. The third hypothesis showed that strategy evaluation has no relationship with productivity. This finding collaborates with Muogbo (2013) who found out that strategic management was not yet a common business practice among manufacturing firms in Anambra State. The findings contradict with Wanjiru (2016) results showed that strategy evaluation has a significant influence on the performance of Sarova town hotels. Similarly, Maroa and Muturi (2015) observed that most floricultural firms evaluated their strategy and strategy evaluation had a significant influence on the performance of flower firms. Also, the findings of Kumar (2015) argue that strategy evaluation is a systematic and rational process that influences the performances of mobile telecommunication firms in Nigeria.

\section{Conclusion}

In the light of the foregoing, this study provides empirical support on dimension of strategic management process and their influence on productivity in the plastic manufacturing sector. The study concluded that strategy formulation, strategy implementation, strategy evaluation makes a 
Journal DOI: www.doi.org/10.46654/RJMP

Article DOI: www.doi.org/10.46654/RJMP.117113

unique contribution to the variation of plastic manufacturing firms' level of productivity to gain edge over rivals in the industry.

\section{Recommendations}

The study recommended that for the plastic firm's to add value to their products and services and the other stakeholders, they should pursue a convincing formulation of policies, mission and strategic plan on how the vendors will achieve greater price levels, and employees to achieve high wage levels, customers to achieve high service levels to improve productivity.

It recommends that plastic manufacturing firms should implement formulated policies and strategies to match with the structure of the organization, increase value relevance and earnings quality for productivity.

The study recommends that plastic firm's should consider strategy evaluation as a continuous process in order to know the level of acceptability of strategies by the stakeholder, to know if the strategies are consistency with internal policies and also to know if the strategies are consonance with external changes that occur in the business arena. 
Journal DOI: www.doi.org/10.46654/RJMP

Article DOI: www.doi.org/10.46654/RJMP.117113

\section{References}

Abdul, N. \& Mas, B. (2016). The relationship between strategicplanning and Malaysian SMEs business performance: The effect of employee participation, implementation incentive and strategy evaluation and control. The International Journal of Business \& Management, 4(3), 353-368.

Ajayi, O.A. (2001). Leadership styles in institutions of higher education: a contingent approach: management in Nigeria. Nigerian Institution of Management Journal, 12, (2), 345-356.

Armstrong, M., \& Taylor, S. (2014). Armstrong's handbook of human resource management practice. Kogan: Page Publishers.

Awan, M. R. \& Mahmood, K. (2009). Relationship among leadership style, organizational culture and employee commitment in university libraries. Library Management, 31(3), 253-266

Avolio, B., Zhu, W., Koh, W. \& Bhatia, P. (2004). Transformational leadership and organizational commitment: mediating role of psychological empowerment and moderating role of structural distance. Journal of Organizational Behavior, 25, 951968.

Bass, B.M., Avolio, B. J., Jung, D.I., \& Berson, Y. (2003). Predicting Unit Performance by Assessing Transformational and Transactional Leadership. Journal of Applied Psychology, 88(2), 207-218

Bass, B.M. \& Avolio, B. J. (2003). Transformational leadership and organizational culture. Public administration quarterly, 12(8), $113-121$.

Barron, J.C. (2001). The Variables ofLeadership: A review and conceptualFramework: The academy of management review, 2(1), 2-9.

Bayo, P. L. \& Redwell, E. E. (2020). Disruptive technologies and productivity of soft drink manufacturing firms in South-South, Nigeria. Nigerian Journal of Management Sciences, 21(1/2), 247-266

Blake and Mouton (1997). The management Grid III. Houston: Gulf Publishing Company

Brockner, J.,Tyler, T., \& Scheneider (1992). The influence of prior commitment to an institution on reactions to perceived unfairness: The higher they are, the harder they fall. Administrative science quarterly, 37(4), 241-261.

Carpenter, M. A., \& Sanders, G. (2009). Strategic Management: a dynamic perspective concepts. Upper Saddle River, NJ: Pearson International. 
Journal DOI: www.doi.org/10.46654/RJMP

Article DOI: www.doi.org/10.46654/RJMP.117113

Donelly, J.H. Gibson, J.L. \& Ivancevich, J.M. (2009). Foundational of Management Business. Publication Inc: Plano

Drucker F. P. (1955). The Principles of Management: William Heinemann Limited: London.

Dunham, B. Randall (1984). Organizational Behaviour People and Process in Management. Richard O.D. Irwin Inc: Homewood Illiniose.

Fielder, F.E. (1964). A Theory of Leadership Effectiveness: McGraw-Hall, New York.

Flippo, R. (1980). Personal Management: Tokyo McGraw-Hill Inc.

Goleman, D. (2000). Leadership that gets results. Harvard Business Review (electronic version) product $\mathrm{N} 4487$

Gilberath, K. (1994). The American management association magazine of March, Management Review, 1(2)22-45

Hersey, P.(1982). Management of Organizational Behaviour: $4^{\text {th }} \quad$ Edition, Eaglewood (Gulf, N.I. Prentice Hall Inc.)

Hunt, S. D. \& Morgan, R.M. (1994). Organizational commitment: One of many commitments or key mediating constructs. Academy of Management Journal, $\quad 37(1), 1568 \quad-1587$

Jaja, S.A. (2003). Pxexis of work behaviour. Pinnache Publisher, Lagos

Koontz, H. and Wurich, H. (1988). Management McGraw-Hill Book Coy: Singaprore.

Lo, M., Ramayahb, T., Minc, H., \& Songand, P. (2010). The relationship between leadership styles and organizational commitment in Malaysia: Role of leader member exchange. Asia Pacific Business Review, 16(1), 79-103.

Lok, P. \& Crawford, J. (1999). The relationship between commitment and organizational culture, subculture, leadership style and job satisfaction in organizational change and development. Leadership and Organization Development Journal, 13(1), 365-373:

Marmaya, N., Hitam, M., Torsiman N., \& Balakrishnan, B. (2011). Employees' perceptions of Malaysian managers' leadership styles and organizational commitment. African Journal of Business Management, 5(1), $1584-1588$

Myloni, B. Harzing, A-W. K., Mirza, H. (2004). Host country specific factors and the transfer of Human resource management practices in multinational companies. International Journal Manpower, 25(6), 518-534.

Nichter, S. \& Goldmark, L. (2009). Small Firm Growth in Developing Countries. Mimeo Publication. 
Journal DOI: www.doi.org/10.46654/RJMP

Article DOI: www.doi.org/10.46654/RJMP.117113

Obioma, G.O. (1987). Research Methodology: Association Certificate in Education Series, Ibadan: Heinemann Educational Books.

Ponnu, C. H. \& Tennakoon, G., (2009). The Association between ethical leadership and employee outcomes. Electronic journal of business ethics and organization studies, 14(1), 21-32.

Stoner, J.A.F. \& Freman, R.F. (1989). Management Prentice Hall: New Dehhi

Urieto, J.E. (1995). Business Statistics: A practical Approach. Paraphics Publishers: Port Harcourt. 